\title{
Introduction to the CVIR Special Issue with a Focus on Oncological Interventions
}

\author{
Thierry de Baère ${ }^{1}$
}

Published online: 11 July 2019

(C) Springer Science+Business Media, LLC, part of Springer Nature and the Cardiovascular and Interventional Radiological Society of Europe (CIRSE) 2019

\section{Dear Readers,}

It is a pleasure for me, as Section Editor of CVIR, to provide our readers with a special issue of the journal dedicated to oncology. The future of interventional radiology obviously includes oncology, and if we want to position ourselves as interventional oncologists, we need to know and understand the basics of oncology and the organ specifics of the cancers we are treating.

This knowledge is needed in order to take care of the patient pathway from referral, to the consultation, through the multidisciplinary tumour board, during the treatment, before discharge and during follow-up consultations. This knowledge is needed in order to improve patient outcomes and to discuss with patients and colleagues what oncology as a whole can offer, and not only what interventional oncology can offer.

Reading this special issue is just the start of gaining the knowledge necessary for oncology, and it is important to recognise that, of course, deeper knowledge is needed: access to an oncological journal is of the utmost importance.

In addition to our mother societies of interventional radiology, we must be part of oncological societies, as well as oncology consensus and guidelines groups, because nobody knows better than we do the benefits and weaknesses of the treatment we deliver.

I hope you will enjoy reading this special issue, where articles have been written by expert authors across the full spectrum of oncology, including medical oncologists, surgeons, radiation therapists and interventional radiologists. Part I will provide basic knowledge in cancer, acting as a simple guide for interventional radiologists. Part II is organ specific, providing the essentials interventional radiologists need to know. All articles from part II are organised according to the same didactic plan in order to facilitate learning and education.

Our challenges are to build the evidence for interventional oncology, and to integrate interventional oncology into the overall treatment of cancer in various therapeutic sequences (induction, combination or adjuvant) with systemic therapies, because today a cancer cure nearly always requires a multidisciplinary approach. Treatment combination is thus a far more pressing concern for all of us than treatment competition.

In this regard, immunotherapy in oncology (also abbreviated to IO) is a field where interventional oncology has a pivotal role to play, because access to the tumour and its microenvironment is important for such treatments. We have to understand immune modulation mechanisms, namely how interventional oncology treatments can expose tumour debris for sensing immune response in nearby tissue and lymph nodes, thus activating $\mathrm{T}$ cells to fight cancer. Interventional oncology can be a minimally invasive way to trigger an immune response in order to enhance the non-enestic effect (treatment of one tumour triggers the response of distant tumours), and to make it happen in a more reliable way.

Thierry de Baère

Thierry.DEBAERE@gustaveroussy.fr

1 Department of Interventional Radiology, Gustave Roussy Cancer Center, 114 rue Edouard Vaillant, Villejuif, France 
I hope that this special supplement will give a good overview to those looking to get more involved in the field, and new insights to those already active in it!

\section{Compliance with Ethical Standards}

Conflict of interest Thierry de Baère is consultant for BTG, Medtronic, Terumo, Boston Scientific, Guerbet, GE Healthcare.

Publisher's Note Springer Nature remains neutral with regard to jurisdictional claims in published maps and institutional affiliations. 